\title{
Editorial: \\ Sustainability of Community ICTs and its Future
}

\author{
Michael Gurstein \\ New Jersey Institute of Technology < editor@ci-journal.net >
}

This, the second issue of the Journal of Community Informatics has the theme of "sustainability". From the perspective of community-based technology initiatives and Community Informatics, "sustainability" is a key concern, without which our efforts and implementations eventually will wither and die. Little will have been accomplished towards our larger task of enabling and empowering communities with information and communications technologies (ICTs). However, defining what is meant by "sustainability" is in itself a task, one that is of key significance for the long-term success of our collective work.

To help explore the challenges of creating sustainable projects, initiatives and ultimately the local changes, developments and even on occasion transformations that will result, we are devoting the second issue of the Journal of Community Informatics to the theme of "Sustainability and Community ICTs".

Whether "sustainability" is purely a matter of financial resources to cover operating and replacement costs, as many project funders seem to suggest; or whether it is a rather more complex intermix of financial, organizational, social and even personal considerations is the subject matter of the articles in this issue, most of which were first presented at the Inaugural Conference of the Community Informatics Research Network (http://www.ciresearch.net) in Prato, Italy in September, 2004.

The range of these papers and the degree of inter-connection between them gives evidence of a healthy research community and a vigorous intellectual climate for our collective work and a considerable degree of interest in getting to a root understanding of "sustainability" and how to influence its future.

"Sustainability" as a concept is conventionally associated with environmental and ecological issues and refers according to the Wikipedia to the "means of configuring civilization and human activity so that society and its members are able to meet their needs and express their greatest potential in the present, while preserving biodiversity and natural ecosystems, and planning and acting for the ability to maintain these ideals indefinitely". However a casual search via Google shows some 85,000 references to "ICT" and "sustainability" excluding "environment".

What is meant by "sustainability" in the ICT context is less a matter of a broad "configuration of civilization" and more to do with day to day slogging by community members in meeting the payroll and keeping the machines running amidst the wear and tear of daily life (both physical and electronic) while always keeping in mind how the technology could be used to respond to the needs (and opportunities) of their local communities. How that is done and not just day by day, but week by week and eventually, year by year will ultimately determine whether ICTs are another development fad or in fact are as fundamentally transformative as many of us anticipate.

Of course, when we are speaking of "sustainability" in the context of ICTs we should perhaps be speaking of "sustainabilities" rather than "sustainability", for there are many dimensions of this issue which go much beyond the simple economic and the meeting of weekly payrolls.

There are, as Hearn et al point out, a variety of organizational, and contextual issues as well as larger technical and industry issues which all impact on "sustainability". Moreover, as Rideout and Reddick discuss concerning the Canadian circumstance, all of these are evolving within a broad policy (and 
government funding) framework that may or may not allow for the effective development of initiatives once-funded even apart from the lack of sustained funding commitment to initiatives once undertaken. Tanner in her paper adds a most interesting and provocative discussion of the role of "emotion" in (and including ICT-enabled) community "sustainability". Ripamonti, de Cindio and Benassi extend this discussion into a broad-based and extremely interesting set of observations and analyses exploring the sustainability issues which cross-cut between on-line community networking and the physical presence and organization of community networks. Their paper gives I believe, what may be the first "business" analysis of a virtual community which, in our context is most notably a thriving community network.

Van Belle and Trusler present an analytic case study of an on-going community ICT project in a Developing Country context, warts and all, and provide very useful insights into the "real world" of development and community ICT; while Musgrave approaches these same issues but at a more "macro" level and within a Developed Country context but interestingly reveals somewhat similar institutional constraints on community ICT initiatives.

The case studies presented from Merkel et al and Thompson further our knowledge of how these issues are being handled in quite specific institutional and economic contexts while the happy conjuncture of the documents presented in the "Notes from the Field" indicates some of the dimensions and broadly perceived significance of the applications and strategies we are discussing.

At a deeper level there are contrasts and similarities across application areas, socio-economic contexts, and organizational forms and missions. These are both startling and revealing and can move us along the path outlined in Simpson's very well argued analysis toward a broader framework for research-based theory development and systematization of experience. Overall, and looked at as an integrated unit rather than as isolated papers, this issue perhaps moves some way in giving the field of Community Informatics both scientific depth and resonsance for policy and practice.

However, to a considerable degree, a discussion on "sustainability" is a measure of the underdevelopment and immaturity of our work and most importantly, I think indicates a clear direction for our activities into the future. Implicit in much of the discussions and analyses presented in this issue are assumptions about the value of ICTs for local communities as "social goods". Following from this there is a further assumption that, given the current or at least future significance and value of these developments, ICTs should be treated as broadly (and tax payer) supportable "public goods". But of course, while we as a community informatics community may accept this argument, it is still very controversial in the larger world and even among those working in the overall field of "Development" whom one might expect to be supporters.

The challenge as I see it in this context, is to make the use of ICTs in communities so transparent in their implementation and so compelling in their application that the issue of "sustainability" in effect disappears. Cell phones have reached a level of disappearance into market place "sustainability" and are moving towards "social good" sustainability at a rapid pace. Their use and increasingly their private and public applications are so necessary that resources are being found to "sustain" them and their infrastructures at the individual and the community level however, poor or remote. To date, the acceptance and use of ICTs has not reached anything like that level and that remains our challenge.

One hopes that when the cycle is completed and the question arises in 3 or 4 years whether to repeat the Journal of Community Informatics' thematic issues with updates, that the matter of "sustainability" of community ICTs, can be gracefully forgotten and we can go on to other and more productive and creative matters.

This issue is dedicated to the memory of Dirk Koning. He made a lasting contribution to all the areas where communities and technology and media move together, a giant of a man in all respects.

${ }^{1}$ http://en.wikipedia.org/wiki/Sustainability 